- Biopsy, imaging or other investigations are often indicated.

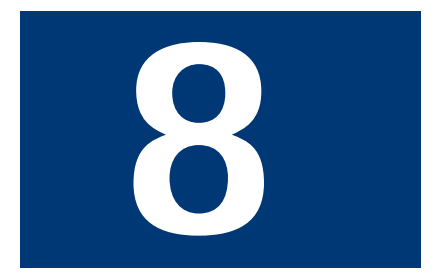

\title{
Oral Medicine - Update for the dental practitioner Lumps and swellings
}

\author{
C. Scully ${ }^{1}$ and D. H. Felix ${ }^{2}$
}

This series provides an overview of current thinking in the more relevant areas of oral medicine for primary care practitioners, written by the authors while they were holding the Presidencies of the European Association for Oral Medicine and the British Society for Oral Medicine, respectively. A book containing additional material will be published. The series gives the detail necessary to assist the primary dental clinical team caring for patients with oral complaints that may be seen in general dental practice. Space precludes inclusion of illustrations of uncommon or rare disorders, or discussion of disorders affecting the hard tissues. Approaching the subject mainly by the symptomatic approach - as it largely relates to the presenting complaint - was considered to be a more helpful approach for GDPs rather than taking a diagnostic category approach. The clinical aspects of the relevant disorders are discussed, including a brief overview of the aetiology, detail on the clinical features and how the diagnosis is made. Guidance on management and when to refer is also provided, along with relevant websites which offer further detail.

\section{ORAL MEDICINE \\ 1. Aphthous and other common ulcers \\ 2. Mouth ulcers of more serious connotation \\ 3. Dry mouth and disorders of salivation \\ 4. Oral malodour \\ 5. Oral white patches \\ 6. Oral red and hyperpigmented patches \\ 7. Orofacial sensation and movement \\ 8. Orofacial swellings and lumps \\ 9. Oral cancer \\ 10. Orofacial pain \\ "Professor, Consultant, Dean, Eastman Dental Institute for Oral Health Care Sciences, 256 Gray's Inn Road, UCL, \\ University of London, London WC1X 8LD \\ ${ }^{2}$ Consultant, Senior Lecturer, Glasgow \\ Dental Hospital and School, 378 \\ Sauchiehall Street, Glasgow G2 3JZ I \\ Associate Dean for Postgraduate Dental \\ Education, NHS Education for Scotland, \\ 2nd Floor, Hanover Buildings, 66 Rose \\ Street, Edinburgh EH2 2NN \\ ${ }^{*}$ Correspondence to: Professor Crispian \\ Scully CBE \\ Email:c.scully@eastman.ucl.ac.uk}

\section{Refereed Paper}

@ British Dental Journal 2005; 199:

763-770
This article discusses neck lumps, salivary gland swellings, and lumps and swellings in the mouth.

\section{NECK LUMPS}

The lymphoid system is the essential basis of immune defences and comprises predominantly bone marrow, spleen, thymus and lymph nodes too. Tissue fluid drains into lymph nodes which act as 'filters' of antigens and, after processing in the nodes, lymph containing various immunocytes drains from the nodes, to lymph ducts and then to the circulation. A lymph node consists of a cortex, paracortex and medulla and is enclosed by a capsule. Lymphocytes and antigens (if present) pass into the node through the afferent lymphatics, are 'filtered' and pass out from the medulla through the efferent lymphatics. The cortex contains B cells aggregated into primary follicles; following stimulation by antigen these develop a focus of active proliferation (germinal centre) and are termed secondary follicles. These follicles are in intimate contact with antigenpresenting dendritic cells. The paracortex contains $\mathrm{T}$ cells, and the medulla contains T and B cells.

\section{Causes of lymph node enlargement}

Many diseases can present with lesions in the neck but the most common are lesions involving the lymph nodes (Table 1).

Nodes enlarge in oral infections or local infections in the drainage area (virtually anywhere in the head and neck). Most common is an enlarged jugulo-digastric (tonsillar) lymph node, inflamed secondary to a viral upper respiratory tract infection. Children and young adults are predominantly affected (Table 2). Enlarged cervical lymph nodes, especially in older people, may also be related to malignant disease in the drainage area (eg carcinoma) or may be a manifestation of systemic disease (eg HIV/AIDS).

\section{Examination of cervical lymph nodes}

Inspection of the neck, looking particularly for swellings or sinuses, should be followed by careful palpation of the thyroid gland and all the lymph nodes, searching for swelling or tenderness.

The examination of lymph nodes in the neck is an important part of every orofacial examination. About one third of all the lymph nodes in the body are in the neck and dental surgeons can often detect serious disease through examining it.

It is prudent to adopt a systematic and methodical approach, examining different lymph node groups in turn:

- Submental

- Submandibular

- Pre-auricular/parotid

- Occipital

- Deep cervical chain.

Both anterior and posterior cervical nodes should be examined as well as other nodes, liver and spleen if systemic disease is a possibility. Most disease in lymph nodes is detected in the anterior triangle of neck, which is bounded superiorly by the mandibular lower border, posteriorly and inferiorly by the sternomastoid 


\begin{tabular}{|c|c|c|c|c|}
\hline \multirow[t]{7}{*}{ Inflammatory } & \multirow[t]{6}{*}{ Infective } & \multirow[t]{2}{*}{ Local } & Bacterial & $\begin{array}{l}\text { Local infections in the } \\
\text { head and neck }\end{array}$ \\
\hline & & & Viral & $\begin{array}{l}\text { Viral respiratory infections } \\
\text { Herpes simplex } \\
\text { Herpes zoster } \\
\text { Herpangina }\end{array}$ \\
\hline & & \multirow[t]{4}{*}{ Systemic } & Bacterial & $\begin{array}{l}\text { Syphilis } \\
\text { Tuberculosis } \\
\text { Atypical mycobacterioses } \\
\text { Cat scratch fever } \\
\text { Brucellosis }\end{array}$ \\
\hline & & & Viral & $\begin{array}{l}\text { Glandular fever syndromes } \\
\text { (EBV, CMV, HIV, HHV-6) } \\
\text { Rubella }\end{array}$ \\
\hline & & & Protozoal & Toxoplasmosis \\
\hline & & & Others & $\begin{array}{l}\text { Mucocutaneous lymph node } \\
\text { syndrome (Kawasaki disease) }\end{array}$ \\
\hline & Non-infective & \multicolumn{2}{|c|}{$\begin{array}{l}\text { Sarcoidosis } \\
\text { Crohn's disease } \\
\text { Orofacial granulomatosis } \\
\text { Connective tissue } \\
\text { diseases }\end{array}$} & \\
\hline \multirow[t]{2}{*}{ Malignancy } & Primary & \multicolumn{2}{|c|}{$\begin{array}{l}\text { Leukaemias } \\
\text { Lymphomas }\end{array}$} & \\
\hline & Secondary & \multicolumn{2}{|c|}{ Metastases } & \\
\hline Other & \multicolumn{3}{|c|}{ Drugs, eg phenytoin } & \\
\hline
\end{tabular}

\begin{tabular}{|c|c|}
\hline Decade & Most common causes of swelling \\
\hline First & $\begin{array}{l}\text { Lymphadenitis due to viral respiratory } \\
\text { tract infection }\end{array}$ \\
\hline Second & $\begin{array}{l}\text { Lymphadenitis due to viral respiratory } \\
\text { tract infection } \\
\text { Bacterial infection } \\
\text { Glandular fever syndromes } \\
\text { HIV infection } \\
\text { Toxoplasmosis }\end{array}$ \\
\hline Third and fourth & $\begin{array}{l}\text { Lymphadenitis } \\
\text { Glandular fever syndromes } \\
\text { HIV infection } \\
\text { Malignancy }\end{array}$ \\
\hline After fourth & $\begin{array}{l}\text { Lymphadenitis } \\
\text { Malignancy }\end{array}$ \\
\hline
\end{tabular}

\begin{tabular}{|c|c|c|c|c|}
\hline Features & $\begin{array}{l}\text { Adolescents and } \\
\text { young adults } \\
\text { mainly }\end{array}$ & $\begin{array}{l}\text { Sore throat, fever, } \\
\text { lymphadenopathy }\end{array}$ & & \\
\hline Causal agents & $\begin{array}{l}\text { Epstein-Barr virus } \\
\text { (EBV) }\end{array}$ & $\begin{array}{l}\text { Cytomegalovirus } \\
\text { (CMV) }\end{array}$ & Toxoplasma gondii & $\begin{array}{l}\text { Human immune } \\
\text { deficiency viruses (HIV) }\end{array}$ \\
\hline Investigations & $\begin{array}{l}\text { Paul-Bunnell Test } \\
\text { EBV antibody titres }\end{array}$ & CMV antibodies & $\begin{array}{l}\text { Sabin-Feldman } \\
\text { dye test } \\
\text { Specific lgM } \\
\text { antibodies }\end{array}$ & $\begin{array}{l}\text { HIV antibody titres } \\
\text { Lymphopenia } \\
\text { T4 (CD4) cell numbers }\end{array}$ \\
\hline
\end{tabular}

muscle, and anteriorly by the midline of the neck. Nodes in this site drain most of the head and neck except the occiput and back of neck. Lymphadenopathy in the anterior triangle of the neck alone is often due to local disease, especially if the nodes are enlarged on only one side.

A limited number of lymph nodes swell usually because they are involved in an immune response to an infectious agent in the area of drainage and nodes are then often firm, discrete and tender, but are mobile (lymphadenitis). The focus of inflammation can usually be found in the drainage area which is anywhere on the face, scalp and nasal cavity, sinuses, ears, pharynx and oral cavity. The local cause may not always be found despite a careful search. For example, children occasionally develop a Staphylococcus aureus lymphadenitis (usually in a submandibular node) in the absence of any obvious portal of infection. Lymph nodes that are tender may be inflammatory, leukaemia or lymphoma; those that are increasing in size and are hard may be malignant.

Lymph nodes may show reactive hyperplasia to a malignant tumour in the drainage area, or swelling because of metastatic infiltration. The latter may cause the node to feel distinctly hard, and it may become bound down to adjacent tissues ('fixed'), may not be discrete, and may even, in advanced cases, ulcerate through the skin. The neoplasms that frequently metastasise to cervical lymph nodes are oral squamous carcinoma (Article 9), nasopharyngeal carcinoma, tonsillar cancer and thyroid tumours.

Usually one or more anterior cervical nodes are involved, often unilaterally in oral neoplasms anteriorly in the mouth, but otherwise not infrequently bilaterally.

More serious is the finding of an enlarged node suspected to be malignant but where the primary neoplasm cannot be found. Nasopharyngeal or tonsillar carcinomas are classic causes of this and an ENT opinion should therefore be sought. Clinically unsuspected tonsillar cancer is a common cause of metastasis in a cervical node of unidentified origin. Biopsy of the tonsil may reveal a hitherto unsuspected malignancy.

Rare causes of cervical metastases include metastases from the stomach or even testicular tumours to lower cervical nodes. However, in some patients with a malignant cervical lymph node, the primary tumour is never located.

Generalised lymphadenopathy with or without enlargement of other lymphoid tissue such as liver and spleen (hepatosplenomegaly), suggests a systemic cause. Lymph nodes may also swell when there are disorders involving the immune system more generally, such as the glandular fever syndromes, HIV/AIDS and related syndromes, various other viral infections; bacterial infections such as syphilis and tuberculosis; and parasites such as toxoplasmosis. In the systemic infective disorders the nodes are usually firm, discrete, tender and mobile. Lymph nodes may also swell in non infective lesions such as sarcoidosis; mucocutaneous lymph node syndrome; and neoplasms such as lymphomas and leukaemias (Table 1). In the latter instances, and in the glandular fever syndromes (where there is lymphadenopathy often together with sore throat and fever; Table 3), there is usually enlargement of many or all cervical lymph nodes and in some there is involvement of the whole reticulendothelial system, with generalised lymph node enlargement (detectable clini- 
cally in neck, groin and axilla) and enlargement of the liver and spleen (hepatosplenomegaly). In the lymphomas particularly the nodes may be rubbery, matted together and fixed to deeper structures.

\section{Management}

A medical opinion is often indicated.

\section{Salivary gland swelling}

Salivary glands usually swell because of inflammation (sialadenitis), which is often viral but may have other causes (Table 4). Obstruction of salivary flow is another common cause (obstructive sialadenitis). Rare causes include salivary gland or other neoplasms.

In children, most salivary gland swellings are caused by mumps. In adults, most swellings of the salivary glands are caused by salivary duct obstruction (typically by a stone) but sialadenitis, Sjogren's syndrome and neoplasms are important causes to be excluded.

\section{Diagnosis of salivary gland swelling}

It can be difficult to establish whether a salivary gland is genuinely swollen, especially in obese patients. A useful guide to whether the patient is simply obese or has parotid enlargement is to observe the outward deflection of the ear lobe which is seen in true parotid swelling.

Diagnosis of the cause is mainly clinical but investigations such as imaging, liver function tests, serology for viral antibodies autoantibodies or biopsy, may be indicated.

\section{Management}

A specialist opinion is usually needed and treatment is of the underlying cause.

Immediate treatment is needed for acute bacterial sialadenitis; under ideal conditions antimicrobial therapy should be determined by results of culture and sensitivity of a sample of pus from the duct. However, as first line therapy, a penicil-

\begin{tabular}{l} 
Table 4 Causes of salivary gland swelling \\
\hline Inflammatory \\
Mumps \\
Ascending sialadenitis \\
Recurrent parotitis \\
HIV parotitis \\
Other infections (eg tuberculosis) \\
Sjogren's syndrome \\
Sarcoidosis \\
Cystic fibrosis \\
Neoplasms (mainly pleomorphic salivary adenoma, but also \\
monomorphic adenomas) \\
Duct obstruction (eg calculus) \\
Sialosis (usually caused by autonomic dysfunction in \\
starvation, bulimia, diabetes, or alcoholic cirrhosis) \\
Deposits rarely \\
(eg amyloidosis and haemochromatosis) \\
Drugs rarely (eg chlorhexidine, methyl dopa, \\
phenylbutazone, iodine compounds, thiouracil, \\
catecholamines, sulfonamides, phenothiazines and protease \\
inhibitors)
\end{tabular}

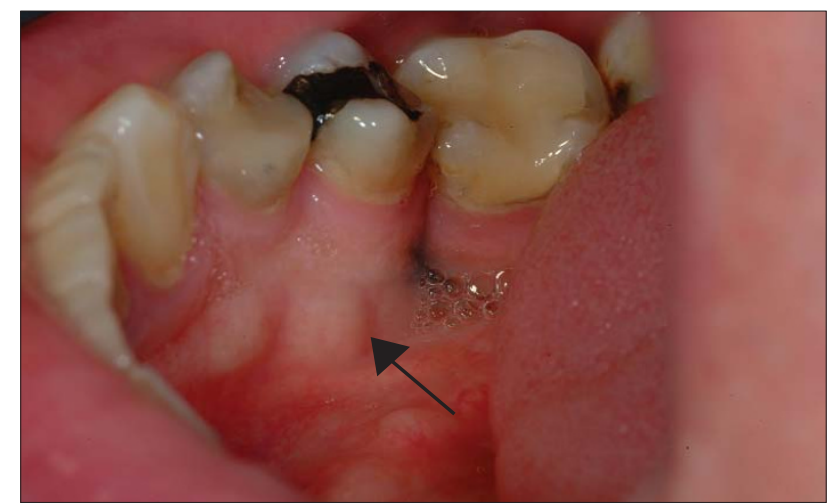

Fig. 1 Torus mandibularis

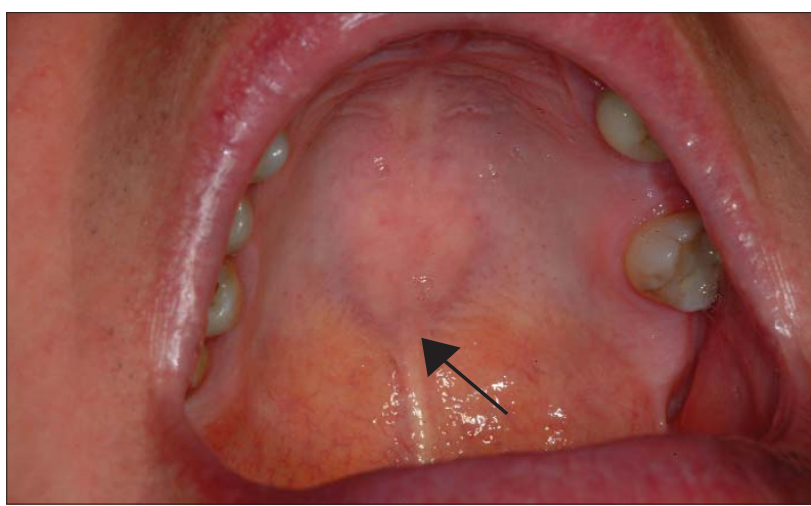

Fig. 2 Torus palatinus
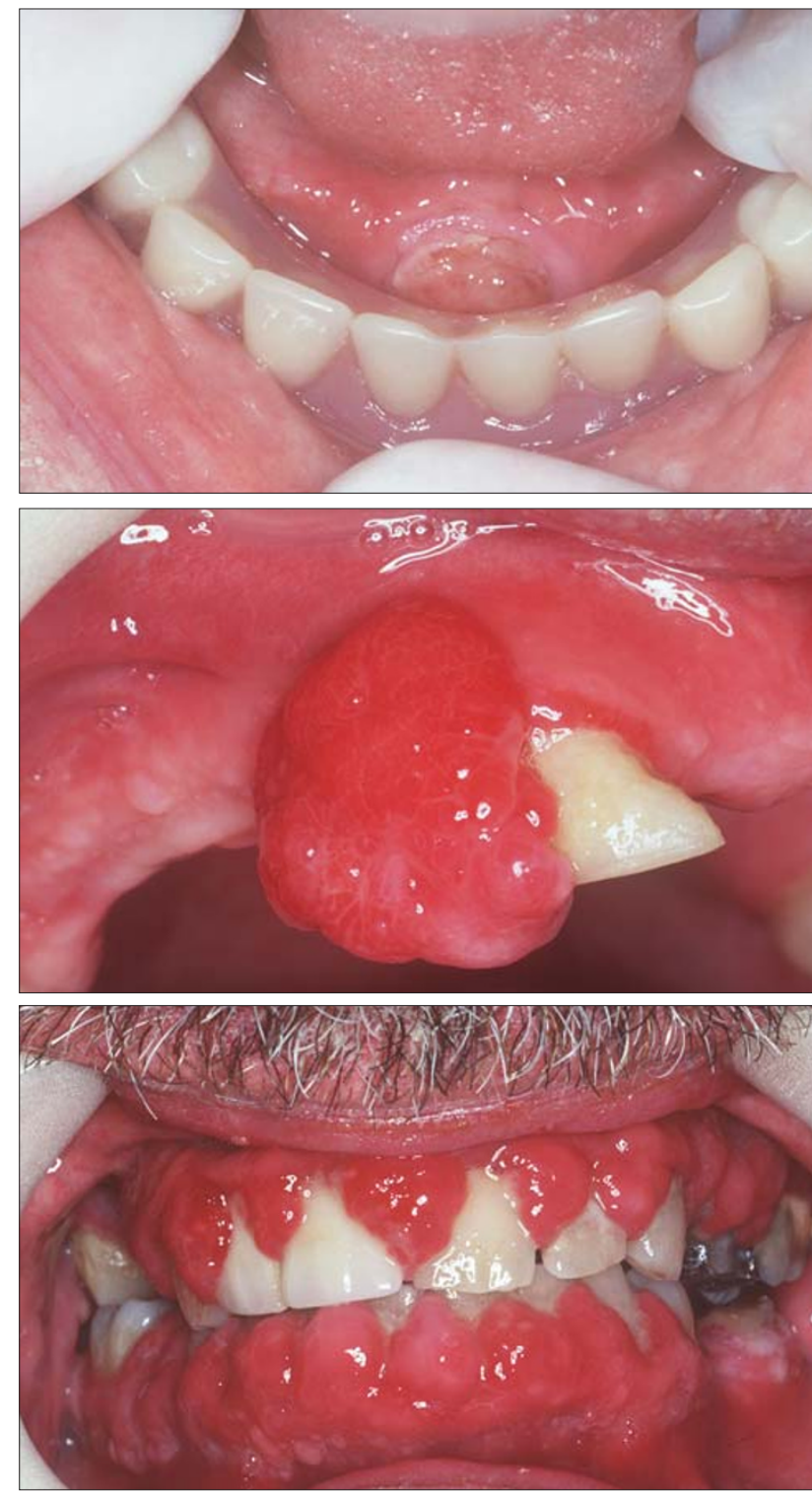

Fig. 3 Dentureand ulceration

Fig. 4 Epulis

Fig. 5 Calcium channel blocker-induced gingival swelling induced hyperplasia 
Fig. 6 Human papillomavirus infection

Fig. 7 Pyogenic granuloma

Fig. 8 Mucocoele in the floor of mouth (ranula)
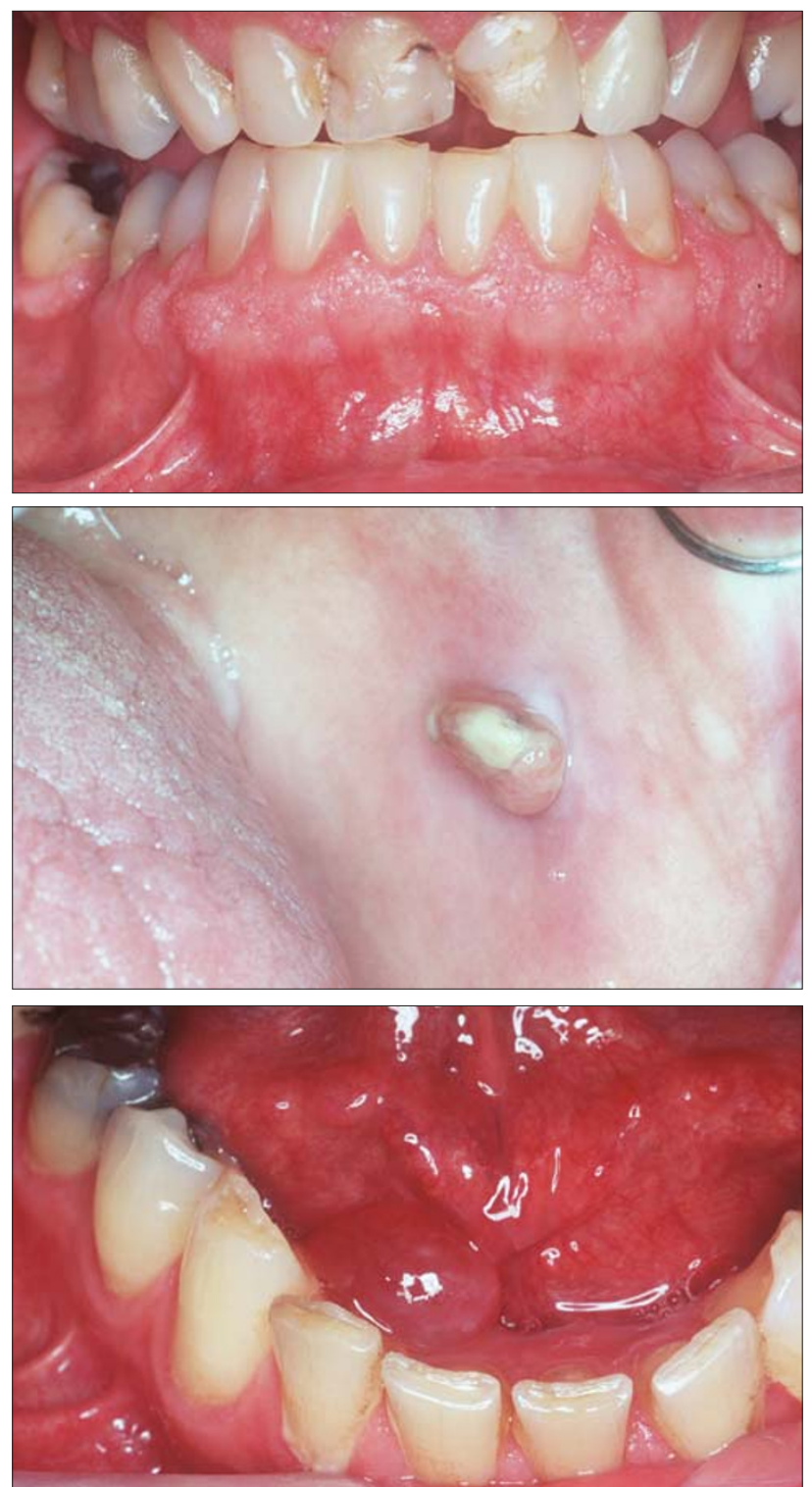

Fig. 9 Vascular hamartoma (haemangioma), dorsum of tongue

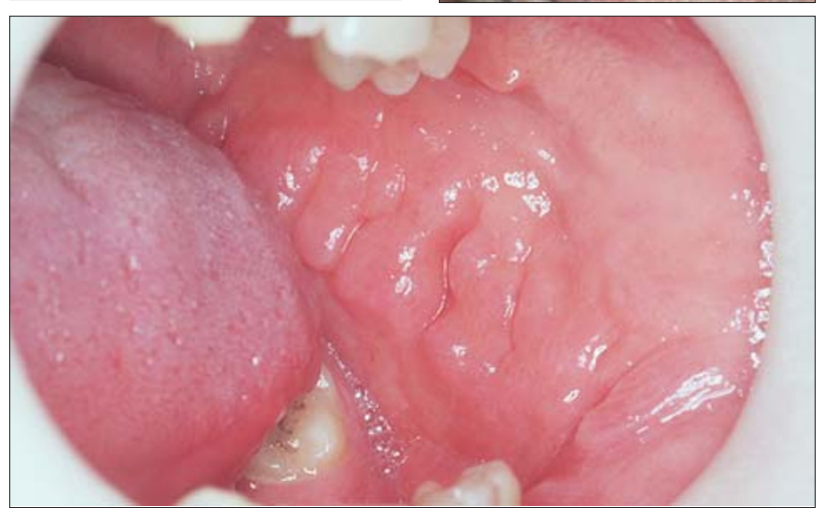

linase-resistant penicillin such as flucloxacillin is appropriate. In patients with penicillin allergy, erythromycin is a suitable alternative. In addition general supportive measures such as analgesia and increased fluid intake are important. Thereafter, specialist referral is generally indicated to identify any predisposing factors.

\section{LUMPS AND SWELLINGS IN THE MOUTH}

Lumps and swellings in the mouth are common, but of diverse aetiologies (Table 5) and some develop into ulcers, as in various bullous lesions (see article 2 ) and in malignant neoplasms (see article 9).

Many different conditions, from benign to malignant, may present as oral lumps or swellings (see tables) including:

- Developmental; unerupted teeth, and tori congenital bony lumps lingual to the mandibular premolars (torus mandibularis; Fig. 1), or in the centre of the palate (torus palatinus; Fig. 2) are common causes of swellings related to the jaws.

- Inflammatory; dental abscess is one of the most common causes of oral swelling. However, conditions characterised by chronic inflammation and granulomas, which can present with lumps or swellings - these include Crohn's disease, orofacial granulomatosis (OFG), and sarcoidosis (discussed below).

- Traumatic; haematoma may cause a swelling at the site of trauma. The flange of a denture impinging on the vestibular mucosa may stimulate a reactive irregular hyperplasia (denture-induced hyperplasia) (Fig. 3).

- Neoplasms; benign epulides (Fig. 4) or malignant tumours such as oral squamous cell carcinoma (OSCC), Kaposi's sarcoma, lymphoma and other neoplasms may present as swellings, as discussed in article 9. Occasionally, metastatic malignant disease may present as a lump.

- Fibro-osseous lesions; fibrous dysplasia and Paget's disease can result in hard jaw swellings.

- Hormonal and metabolic; pregnancy may result in a gingival swelling (pregnancy epulis)

- Drug-induced; a range of drugs can produce gingival swelling - most commonly implicated are phenytoin, calcium channel blockers and ciclosporin (Fig. 5).

- Allergic lesions; angioedema in particular can cause swellings.

- Viral lesions; papillomas, common warts (verruca vulgaris), and genital warts (condyloma acuminatum) are all among the lumps caused by human papillomaviruses (HPV; Fig. 6).

Causes of lumps and swellings according to site Carcinomas and other malignant neoplasms (See article 9) can present in any site.

\section{Gingiva}

Sometimes, hyperplasia is congenital. Rapidly developing localised lumps, usually associated 


\begin{tabular}{|c|c|}
\hline \multicolumn{2}{|c|}{$\begin{array}{l}\text { Table } 5 \text { Main conditions which may present as lumps } \\
\text { or swellings in the mouth }\end{array}$} \\
\hline Normal anatomy & $\begin{array}{l}\text { Pterygoid hamulus } \\
\text { Parotid papillae } \\
\text { Lingual papillae (foliate and circumvallate) }\end{array}$ \\
\hline Developmental & $\begin{array}{l}\text { Unerupted teeth } \\
\text { Odontogenic cysts } \\
\text { Eruption cysts } \\
\text { Developmental cysts (eg thyroglossal, } \\
\text { dermoid) } \\
\text { Haemangioma } \\
\text { Lymphangioma } \\
\text { Maxillary and mandibular tori } \\
\text { Hereditary gingival fibromatosis } \\
\text { Lingual thyroid }\end{array}$ \\
\hline Inflammatory & $\begin{array}{l}\text { Abscess } \\
\text { Cellulitis } \\
\text { Cysts } \\
\text { Insect bites } \\
\text { Sialadenitis } \\
\text { Pyogenic granuloma } \\
\text { Chronic granulomatous disorders } \\
\text { Orofacial granulomatosis } \\
\text { Crohn's disease } \\
\text { Sarcoidosis }\end{array}$ \\
\hline Traumatic & $\begin{array}{l}\text { Denture granulomata } \\
\text { Epulis } \\
\text { Fibroepithelial polyp } \\
\text { Haematoma } \\
\text { Mucocele } \\
\text { Surgical emphysema }\end{array}$ \\
\hline Neoplasms & $\begin{array}{l}\text { Carcinoma } \\
\text { Leukaemia } \\
\text { Lymphoma } \\
\text { Myeloma } \\
\text { Odontogenic tumours } \\
\text { Minor salivary glands } \\
\text { Others }\end{array}$ \\
\hline Fibro-osseous & $\begin{array}{l}\text { Cherubism } \\
\text { Fibrous dysplasia } \\
\text { Paget's disease }\end{array}$ \\
\hline Hormonal & $\begin{array}{l}\text { Pregnancy epulis/gingivitis } \\
\text { Oral contraceptive pill gingivitis }\end{array}$ \\
\hline Metabolic & $\begin{array}{l}\text { Amyloidosis } \\
\text { Other deposits }\end{array}$ \\
\hline Drugs & $\begin{array}{l}\text { Phenytoin } \\
\text { Calcium channel blockers } \\
\text { Ciclosporin }\end{array}$ \\
\hline Allergic & Angioedema \\
\hline Infective & HPV \\
\hline
\end{tabular}

\section{Table 6 Main features of OFG}

- Ulcers

- Facial or labial swelling

- Angular cheilitis

- Lip fissures

- Mucosal tags

- 'Cobblestone' proliferation of the mucosa

- Gingival swelling

with discomfort, are most likely to be abscesses, usually a dental abscess. Other localised swellings are usually inflammatory, such as the pyogenic granuloma (Fig. 7) or neoplastic.

Most generalised gingival swellings are due to hyperplasia with oedema related to plaque deposits, occasionally exacerbated by hormonal changes (puberty, pregnancy) or drugs. Such changes often develop slowly - over weeks rather than days - and are usually without discomfort.
There are very few serious causes of generalised enlargements of the gingivae appearing spontaneously or rapidly, but leukaemia is one prime example.

\section{Palate}

Lumps of the hard palate may develop from structures within the palate (intrinsic) or beyond it (extrinsic). Thus, for example, torus palatinus (Fig. 2) is an intrinsic bone lesion, whereas a dental abscess pointing on the palate (usually from the palatal roots of the first and second maxillary molars, or from upper lateral incisors) is extrinsic. Unerupted teeth, especially permanent canines, or second premolars are relatively common. Other causes of palatal swellings are uncommon but it should be remembered that the palate is the second most common site (after the parotid) for pleomorphic adenomas and other salivary neoplasms. Invasive carcinoma from the maxillary sinus may produce a palatal swelling. Kaposi's sarcoma, typical of HIV/AIDS, may also present as a lump in the palate, or elsewhere. Developing unilateral hard palatal swellings, characteristically disturbing the fit of an upper denture in older patients, may denote Paget's disease.

\section{Floor of mouth}

Swellings in the floor of the mouth are more likely to arise from structures above the mylohyoid muscle than below it. The commonest swellings in the floor of the mouth are dentureinduced hyperplasia or a salivary calculus.

Other lesions producing swellings in this area are a mucocele (known as ranula because of the resemblance to a frog's belly; Fig. 8) and neoplasms of the sublingual salivary gland (usually malignant), but these are relatively uncommon. Patients occasionally describe a lump which proves to be a swelling of the lingual aspect of the mandible (more characteristic of ameloblastoma than of dental abscesses or cysts). Swellings of the submandibular salivary gland and adjacent lymph nodes may occasionally be described by patients as being in the floor of the mouth. However, only very large swellings below the mylohyoid muscle are likely to produce a bulge in the mouth. Swellings in the floor of the mouth may inhibit swallowing and talking.

Mandibular tori (Fig. 1) produce bony hard swellings lingual to the lower premolars.

\section{Tongue and buccal mucosa}

Discrete lumps may be of various causes - congenital (Fig. 9; haemangioma), inflammatory, traumatic or neoplastic.

The tongue may be congenitally enlarged (macroglossia) in, for example, Down syndrome, or may enlarge in angioedema, gigantism, acromegaly or amyloidosis.

Causes of swellings include haematomas from trauma (such as occasional biting), infections, angioedema, fibro-epithelial polyps, fibrous lumps, mucoceles (Fig. 9), vesiculobullous lesions, and occasionally insect bites. 
Fig. 11 Orofacial granulomatosis with chronic lip swelling

Fig. 12 Neurofibromatosis, face

Fig. 13 Neurofibromatosis, upper lip

Fig.14 Minor salivary gland neoplasm
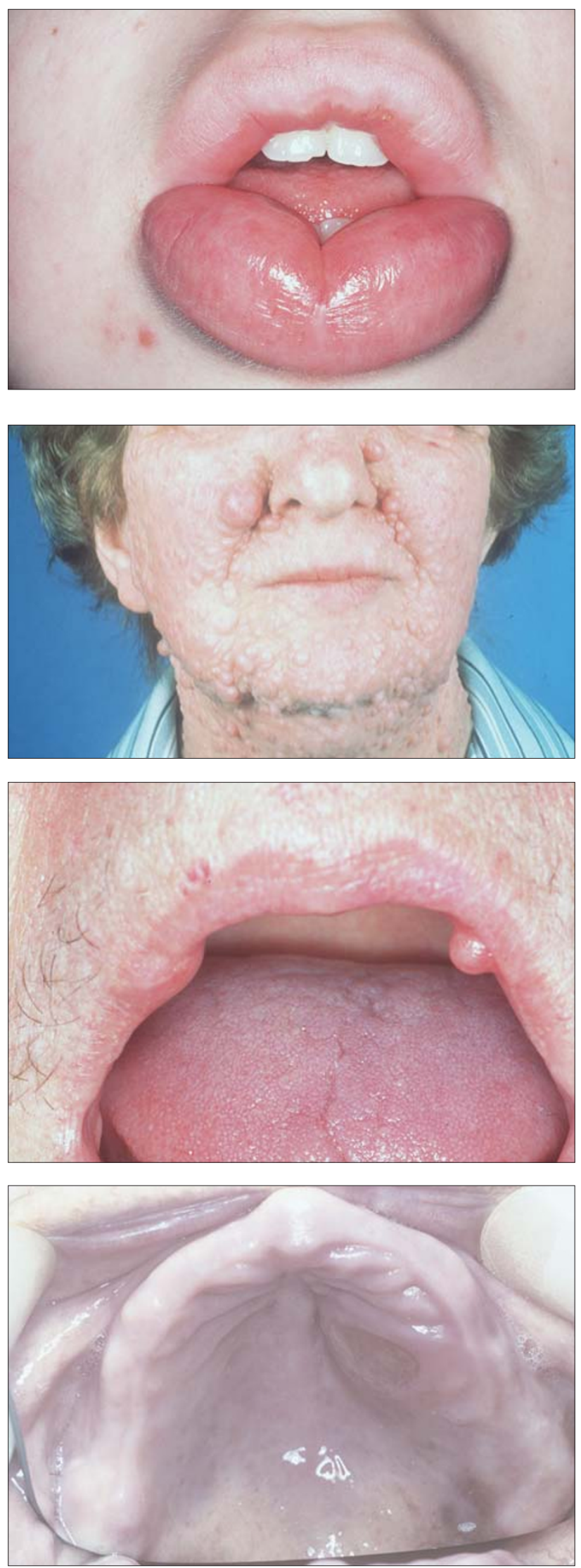

Systemic conditions such as Crohn's disease, orofacial granulomatosis and occasionally sarcoid may produce widespread irregular thickening (cobblestoning) of the cheek mucosa (Fig. 10) or the lips (Fig. 11).

Some 'lumps' become ulcers, as in various bullous lesions, in primary and tertiary syphilis and in malignant neoplasms.

The flange of a denture impinging on the vestibular mucosa may stimulate a reactive irregular hyperplasia - the so-called denture granuloma or denture-induced hyperplasia (Fig. 3). Salivary neoplasms in the lip may simulate, but are usually harder than, mucous cysts. Mucoceles are uncommon in the upper lip; discrete swellings there may well be salivary gland neoplasms.

\section{Diagnosis of the cause of a lump or swelling}

When patients refer to a lump in the mouth it is important to establish when it was first noticed. The tongue often detects even very small swellings and patients may also notice a lump because it is sore. Most patients have only a passing interest in their mouths but some examine their mouths out of idle curiosity, some through fear (perhaps after hearing of someone with 'mouth cancer'). Indeed it is not unknown for some individuals (including dental staff!) to discover and worry about the parotid papilla, foliate papillae on the tongue, or the pterygoid hamulus. The medical history should be fully reviewed, and there should be a thorough examination, since some systemic disorders may be associated with intra-oral or facial swellings (Fig. 12).

Features of a lump which can be diagnostically useful are:

a) The number of lesions - particularly with regard to whether the lesion is bilaterally symmetrical and thus possibly anatomical;

b) Alteration in size;

c) Any discharge from the lesion (clear fluid, pus, blood).

d) When patients refer to a lump in the mouth, it is important to establish when it was first noticed.

Important features to consider when making the provisional diagnosis of the cause of a lump or swelling include:

- Position. The anatomical position should be defined and the proximity to other structures (eg teeth) noted.

- Midline lesions tend to be developmental in origin (eg torus palatinus).

- Bilateral lesions tend to be benign (eg sialosis - salivary swelling in alcoholism, diabetes or other conditions).

- Most neoplastic lumps are unilateral.

Other similar or relevant changes elsewhere in the oral cavity should be noted.

- Size. The size should always be measured and recorded. A diagram or photograph may be helpful.

- Shape. Some swellings have a characteristic shape which may suggest the diagnosis: thus a parotid swelling often fills the space between the posterior border of the mandible and the mastoid process.

- Colour. Brown or black pigmentation may be due to a variety of causes such as a tattoo, naevus or melanoma. Purple or red may be 
due to a haemangioma, Kaposi's sarcoma or giant-cell lesion.

- Temperature. The skin overlying acute inflammatory lesions, such as an abscess, or a haemangioma, is frequently warm.

- Tenderness. Inflammatory swellings such as an abscess are characteristically tender, although clearly palpation must be gentle to avoid excessive discomfort to the patient.

- Discharge. Note any discharge from the lesion (eg clear fluid, pus, or blood), orifice, or sinus.

- Movement. The swelling should be tested to determine if it is fixed to adjacent structures or the overlying skin/mucosa - such as may be seen with a neoplasm.

- Consistency. Palpation showing a hard (indurated) consistency may suggest a carcinoma. Palpation may cause the release of fluid (eg pus from an abscess) or cause the lesion to blanch (vascular) or occasionally cause a blister to appear (Nikolsky sign) or to expand. Sometimes palpation causes the patient pain (suggesting an inflammatory lesion). The swelling overlying a bony cyst may crackle (like an egg-shell) when palpated or fluctuation may be elicited by detecting movement of fluid when the swelling is compressed. Palpation may disclose an underlying structure (eg the crown of a tooth under an eruption cyst) or show that the actual swelling is in deeper structures (eg submandibular calculus).

- Surface texture. The surface characteristics should be noted: papillomas have an obvious anemone-like appearance; carcinomas and other malignant lesions tend to have a nodular surface and may ulcerate. Abnormal blood vessels suggest a neoplasm.

- Ulceration. Some swellings may develop superficial ulceration such as squamous cell carcinoma. The character of the edge of the ulcer and the appearance of the ulcer base should also be recorded.

- Margin. Ill-defined margins are frequently associated with malignancy, whereas clearly defined margins are suggestive of a benign lesion.

- Number of swellings. Multiple lesions suggest an infective or occasionally developmental, origin. Some conditions are associated with multiple swellings of a similar nature, eg neurofibromatosis (Fig. 12).

\section{Investigations}

The nature of many lumps cannot be established without further investigation.

- Any teeth adjacent to a lump involving the jaw should be tested for vitality, and any caries or suspect restorations investigated.

- The periodontal status of any involved teeth should also be determined.

- Imaging of the full extent of the lesion and possibly other areas is required whenever lumps involve the jaws. OPT and special radiographs (eg of the skull, sinuses, salivary gland function), computerised tomography
(CT scans) or magnetic resonance imaging (MRI), or ultrasound may, on occasions, be indicated. Photographs may be useful for future comparison.

- Blood tests may be needed, particularly if there is suspicion that a blood dyscrasia or endocrinopathy may underlie the development of the lump.

- Biopsy is often required (Fig. 13) especially if the lesion is single and chronic, since it may be a neoplasm (Fig. 14) or other serious condition.

\section{CHRONIC GRANULOMATOUS CONDITIONS}

There are a number of patients who present with chronic swellings or lumps, which on biopsy prove to have histological evidence of noncaseating epithelioid cell granulomas. These conditions include orofacial granulomatosis, Crohn's disease, and sarcoidosis.

\section{Orofacial granulomatosis}

Orofacial granulomatosis (OFG) is an uncommon but increasingly recognised condition seen mainly in adolescents and young adults which usually manifests with chronic facial and/or labial swelling, but which can also manifest with angular stomatitis and/or cracked lips, ulcers, mucosal tags, mucosal cobble-stoning, or gingival swelling (Figs 10 and 11; Table 6).

Some patients with similar features have, or develop, gastrointestinal Crohn's disease or sarcoidosis.

The aetiology of OFG is unknown but in some there is a postulated reaction to food or other antigens (particularly to additives/preservatives such as benzoates or cinnamaldehyde), or metals such as cobalt. Most patients appear to develop the problem in relation to dietary components such as chocolate, nuts, cheese or food additives.

Conditions related to OFG include Miescher's cheilitis - where lip swelling is seen in isolation, and Melkersson-Rosenthal syndrome - where there is facial swelling with fissured tongue and recurrent facial palsy.

\section{Diagnosis}

Diagnosis is clinical, supported by blood tests, endoscopy, imaging and biopsy to differentiate from Crohn's disease, sarcoidosis, tuberculosis and foreign body reactions. Specialist care is usually indicated.

\section{Management}

Management is to eliminate allergens such as chocolate, nuts, cheese, cinnamaldehyde or food additives and treat lesions with intralesional corticosteroids or occasionally topical tacrolimus, systemic clofazimine or sulfasalazine.

\section{Useful websites}

http://www.emedicine.com/derm/topic72.htm

\section{Crohn's disease}

Crohn's disease is a chronic inflammatory idiopathic granulomatous disorder. Many causal 


\section{Patients to refer}

Suspected malignancy including Lymphoma

Suspected metastatic disease Unexplained lymphadenopathy Orofacial granulomatosis factors have been hypothesised but not proved. Crohn's disease affects mainly the small intestine (ileum) but can affect any part of the gastrointestinal tract, including the mouth.

About 10\% of patients with Crohn's disease of the bowel have oral lesions. Oral lesions may be seen in the absence of any identifiable gut involvement and are the same as those seen in OFG - reddish raised lesions on the gingiva, hyperplastic folds of the oral mucosa (thickening and folding of the mucosa producing a 'cobblestone type' of appearance, and mucosal tags), ulcers (classically linear vestibular ulcers with flanking granulomatous masses), facial swelling and angular cheilitis. There may also be features of gastrointestinal involvement such as abnormal bowel movements, abdominal pain, rectal bleeding or weight loss.

\section{Diagnosis}

Oral biopsy, haematological, gastrointestinal and other investigations may be required in suspected Crohn's disease especially to exclude sarcoidosis. Specialist care is usually indicated. Histologically, the epithelium is intact but thickened, with epithelioid cells and giant cells surrounded by a lymphocytic infiltration.

\section{Management}

Topical or intralesional corticosteroids may effectively control the oral lesions but more frequently systemic corticosteroids, azathioprine or salazopyrine are required.

\section{Sarcoidosis}

Sarcoidosis is a multi-system granulomatous disorder, of unclear aetiology, which most commonly affects young adult females, especially AfroCaribbeans.

Sarcoidosis typically causes bilateral hilar lymphadenopathy, pulmonary infiltration and impaired respiratory efficiency, skin and eye lesions but can involve virtually any tissue. Because of its vague and protean manifestations, sarcoidosis appears to be under-diagnosed. Gingival enlargement, or oral swellings may be seen but sarcoidosis can involve any of the oral tissues and has a predilection for salivary glands, causing asymptomatic enlargement of the major salivary glands and some have xerostomia. The association of salivary and lacrimal gland enlargement with fever and uveitis is known as uveoparotid fever (Heerfordt's syndrome).

\section{Diagnosis}

The most helpful investigations include:

- Chest radiography (for enlarged hilar lymph nodes)

- Raised levels of serum angiotensin-converting enzyme (SACE) in acute disease

- A positive gallium or PET (positron emission tomography) scan of lacrimal and salivary glands

- Labial salivary gland biopsy (for histological evidence of non-caseating epithelioid cell granulomas).

\section{Management}

Patients with sarcoidosis but only minor symptoms often require no treatment. If there is active ocular disease, progressive lung disease, hypercalcaemia, or cerebral involvement or other serious complications, corticosteroids are given. 